\title{
Linguagem e Tradição em Carlo Levi: marcas do arcaico no sul italiano*
}

Amarilis Gallo Coelho - Fac. Letras/UFRJ**

RESUMO: Carlo Levi, escritor italiano que objetiva documentar as peculiaridades e a diversidade social de seu país, utiliza, além do léxico colorido constante em sua obra, outros artifícios de expressão, tais como o emprego de formas-símbolo, como pedra, e amostras de linguagem, que caracterizam não só o plurilinguismo italiano, mas também a manutenção do arcaico e da história, através dos hábitos linguísticos e sociais. Pelo uso estilístico e a constatação real de formas greco-latinas, assim como seus reflexos nos dialetos locais, Levi retrata com autenticidade 0 apego à tradição e a imobilidade espaço-temporal do homem meridional italiano.

Carlo Levi (1902-1975) foi um dos escritores italianos mais envolvidos com a causa meridionalista, ou seja, comprometido com os problemas ligados ao sul da Itália. Uma sensibilidade acentuada, unida à formação de artista plástico, influenciou seu estilo narrativo desde o início de sua produção literária, principalmente no tocante à obra Cristo si è fermato a Eboli (1945). Esta obra tem a conotação de documentário do período transcorrido em exílio (era anti-fascista) na Lucania, província da Campania, região ao sul da Itália, onde permaneceu durante dois anos (1935-1936).

\footnotetext{
*Recebido para publicação em 1997.

** Profa. do Departamento de Letras Neolatinas da Faculdade de Letras da Universidade Federal do Rio de Janeiro.
} 
A permanência na Lucania possibilitou ao autor uma profunda experiência humana, durante a qual conseguiu instituir com os pobres camponeses do lugar, uma relação de afetuosa participação. Exerceu sua profissão médica a favor daquela gente, mesmo que em situação precária, pela falta de remédios e instrumentos apropriados, recebendo em troca, o reconhecimento da população camponesa, que ele define como sendo atemporal, não reconhecida em sua história e em seus valores, pela burguesia e pelo Estado.

Para compreender plenamente como Levi edifica sua obra, é necessário ter em mente que cada palavra e cada estrutura de significação tem, além do significado explícito, aquele implícito, em afinidade com o espírito mágico e transcendental do espaço narrado.

Ao nos aprofundarmos na obra de Carlo Levi como um todo, constatamos alguns pontos recorrentes em sua representação do solo meridional italiano, como a preocupação em comunicar-se, em inteirar-se de tudo que possa ampliar suas impressões daquele espaço e daquela gente. Em Cristo si è fermato a Eboli (Cristo parou em Eboli), sua linguagem destaca constantemente certas condições existenciais, com o contínuo recurso a termos e formas idiomáticas que, direta ou indiretamente, formam o quadro sócio-cultural da região onde passou o período de exílio: "Lucus a non lucendo, realmente, hoje: a Lucania, a terra dos bosques, é toda árida ${ }^{1}$." (LEVI a, 1990:6)

O léxico levinista privilegia signos específicos de cor local, ressaltando formas e cores, assim como expressões dialetais ou arcaicas, que vão gradativamente compondo os campos semânticos recorrentes também em outras obras, como Tutto il miele è finito (Todo o mel acabou) e Le parole sono pietre (As palavras são pedras).

Um dos motivos mais comuns em Levi, que ocorre predominantemente em Cristo si è fermato a Eboli é a compresença espaço-

\footnotetext{
${ }^{1}$ Todas as citações em português receberam tradução da autora.
} 
temporal, ou seja, a permanência do passado arcaico no presente, não só como dado cultural de tradição, mas como signo de imobilidade da comunidade rural italiana:

"Era aquele esquema clássico, a recordação de uma arte antiga, reduzida ao pobre resíduo da arte popular, ou um espontâneo, originário renascer, uma linguagem, natural nestas terras, onde a vida é uma tragédia sem teatro?" (LEVI a, 1990:204)

Esta concepção da imobilidade temporal baseia-se na rotina imutável da vida camponesa, ressaltando o contraste entre aqueles que produzem, sem esperança de progressão social e aqueles que desfrutam, inconscientes das necessidades básicas da população menos privilegiada: "Assim se estabeleceu aquele modus vivendi, que durou depois para sempre." (LEVI a, 1990:207)

Em seus longos passeios e visitas, o escritor observa e cataloga suas impressões, baseadas em diálogos espontâneos, repletos de palavras grávidas de significação, que aos poucos desdobram-se em outros significados: "O cupo-cupo é um instrumento rudimentar, feito de uma panela ou de uma caixa de lata." (LEVI a, 1990:173) Uma provável explicação para a origem desta palavra seria a forma latina cupa, ae = vasilha grande de madeira. ${ }^{2}$

A atenção dada a expressões de origem latina ou grega, como signos do arcaico, principalmente no tocante a objetos de uso pessoal e utensílios domésticos ocorre em outras obras, como em Tutto il miele è finito: "(..) personagens realísticos, com as armas, os instrumentos, e a tiracolo, na bainha guerreira dos pastores, a faca, sa leppa: as marcas de uma civilização primitiva e mágica." (LEVI b, 1990:58) A expressão lèppa é um substantivo feminino, que em sardo significa "faca" ou "navalha"; em calabrês, "lâmina longa de faca"; no Lácio, em Roma, 
com a forma sleppa, "faca". Todos estes usos (e outros derivados, em uso na gíria siciliana (lappanedda, lapparedda $=$ coltello, faca) ) nos fazem voltar às origens gregas: lepis, lépos, cortador, lâmina de metal etc... ${ }^{3}$

Através do registro de certos personagens, Levi sintetiza, de maneira às vezes irônica, a situação de inferioridade em que se encontra o homem meridional. Tal ocorre, por exemplo, quando de seus diálogos com o médico ou o pároco do vilarejo:

"É uma cidade de asnos, esta, não de cristãos, - disse-me, convidando-me a entrar na igreja. - O senhor sabe o verdadeiro latim? Gallianus, Gallianellus/ Asinus et asellus/ Nihil aliud in sella/ Nisi joseph Trajella." (LEVI a, 1990:37) :

Ou ainda, de outras vezes:

"A gente é pior que a terra. Profanum vulgus." (LEVI a, 1990:38) "Pax in terra hominibus bonae voluntatis, (...) Vocês não sabem o latim? Quer dizer que hoje, véspera de Natal, deveriam trazer-me uma cabra de presente, segundo o costume(...)não têm boa vontade, não têm a paz e a bênção do Senhor." (LEVI a, 1990:179)

Portanto, alguns personagens, mais do que outros, assumem papel de informantes e de modelos para a composição do quadro gradativamente pintado pelo autor: o representante da Igreja no local, por exemplo, utiliza na maior parte das vezes, expressões em latim, no desejo de destacar-se, talvez, daquela massa indistinta: "Me apresentou sua mãe(...) estava vetula et infirma." (LEVI a, 1990:80) "Não fiz mais nada desde que estou aqui, in partibus infidelium." (LEVI a, 1990:82) Consequentemente, certas estruturas do latim passam a fazer parte do vocabulário do povo, no desejo de elevação social, e o autor as enfatiza, muitas vezes, usando-as como suporte 
temático: "Don Luigino teria podido exercitar seu oficio pro forma." (LEVI a, 1990:171) "Quando a missa acabou, no Ite missa est..." (LEVI a, 1990:176)

Carlo Levi objetiva acompanhar de perto tudo aquilo que represente de maneira mais autêntica a sociedade que observa, desde simples expressões como: "Addò vades? Aonde vais?" (LEVI a, 1990:68) até as crenças mais peculiares do lugar:

"A magia popular cura um pouco todas as doenças; e, quase sempre pela única virtude de fórmulas e de encantamentos. Algumas são, pelo que sei, de origem local; outras pertencem ao corpus clássico dos formulários mágicos, chegados aqui em baixo quem sabe quando e quem sabe por que meios (...) o mais comum era o abracadabra." (LEVI a, 1990:209)

Esta palavra, segundo Carlo Levi, representa para aquela gente humilde mais do que um simples encantamento; é aquela que está presente nos amuletos e que pode abrir os caminhos e trazer a cura e a esperança. A origem desta palavra apresenta várias conjecturas: abracadabra é um substantivo masculino "palavra mágica da antiguidade"; gr. abrakadabra que passou ao latim abracadabra, tendo como origem provável: 1 frase hebraica habraha dabar 'abençoe o objeto ' (Shipley -Word Origins); 2.termo artificial, feito pelos mágicos da Idade Média, onde entra a palavra grega abráxas, de origem persa, nome de um deus protetor dos feiticeiros (Weekley-The Romance of Words). ${ }^{4}$

Alguns detalhes recebem, por parte do autor, maior atenção, os quais podemos considerar super-signos meridionais: entre tantos, destacamos aqui o signo casa, que assume conotações as mais diversas e participa de metáforas e simbologias profundas na escritura

${ }^{4}$ BUENO, Silveira. Grande Dicionário Elimológico-Prosódico da Lingua Portuguesa, S.P.: Ed. Saraiva. 1968. v.I, p. 20 
levinista: "As casas dos camponeses são todas iguais, feitas de um só cômodo, que serve de cozinha, de quarto de dormir e quase sempre também de estábulo para os animais pequenos, quando não existe, com este propósito, uma casinha que se chama em dialeto, com palavra grega, o catoico." (LEVI a, 1990:106) gr.katoikia 'habitação', residência"5 Carlo Levi demonstra, através de seu estilo, com explicações pormenorizadas, o caráter sócio-linguístico de sua narrativa, muitas vezes enriquecido por interessantes comentários de cunho mitológico, artístico ou histórico: "A pietas di Enea não podia ser compreendida pelos antigos italianos, que viviam nos campos com os animais." (LEVI a, 1990:124)

Certas palavras tornam-se quase formas concretas na arquitetura daquele espaço, pela conotação fixa e simbólica, já conferida pelo uso local: "Nestes vilarejos,(...) uma palavra não é nunca uma convenção ou um sopro de vento, mas uma realidade, uma coisa que age." (LEVI a, 1990:124) Neste contexto, citamos a palavra crai, forma-símbolo ligada profundamente ao tema da passividade e da omissão, características da desigualdade social, documentada por Carlo Levi:

A outra palavra, que volta sempre nas conversas é crai, o cras latino, amanhã. Tudo aquilo que se espera, que deve chegar, que deve ser feito ou mudado, é crai. Mas crai significa mai significando 'nunca.' (LEVI a, 1990:163) O escritor enfatiza as nuances de uso da palavra, como sempre, demonstrando a ironia e o humor que muitas vezes os próprios personagens, no caso, bastante reais, conferem ao seu próprio modus vivendi. Crai é 'amanhã' e 'sempre'; mas o dia depois de amanhã é pescrai e o dia depois é pescrille; depois vem pescruflo, e depois maruflo e maruflone; e o sétimo dia é maruflicchio.

${ }^{5}$ The Oxford Dictionary of Modern Greek (Greek-English). Compilado por J.T.Pring. Oxford: Clarendon
Press. 1968. p. 95. 
Mas esta: exatidão de termos tem mais do que tudo o valor de ironia." (LEVI a, 1990:184)

Os costumes locais são outra inesgotável fonte de observação para Levi, que identifica, através da linguagem, hábitos de convivência solidária, que retratam uma das características mais marcantes no homem meridional italiano, ou seja, o apego às tradições, como única forma de manter a cultura e o sentimento comunitário:

"Era o sanaporcelle (lat.porcella, ae 'porca nova'). Sanar as porquinhas significa castrá-las, as quais não devem procriar, para que engordem mais, e tenham carnes mais macias." (LEVI a, 1990:167) Da mesma forma, na obra $\underline{\text { Tutto }}$ il miele è finito : "É uma história que se vai compondo neles mesmos, e precisando-se enquanto falam, onde os documentos são a memória, a poesia popular, os modos do costume, como sa socia. Os pastores, antigamente, que criavam rebanhos de porcos, há tantos anos atrás, costumavam matá-los todos em um único dia, e guardavam todo o toucinho em casa, enquanto alguém distribuía um pouco de carne pela vizinhança. Sa socía, ou succía, dizem alguns, vem de sugar, consumir tudo em um dia. Ou vem, dizem outros, de sociedade. Será assim? - Suzía, - conclue o pastor, - é uma palavra antiga." (LEVI b, 1990:108)

Outra provável explicação para a origem desta palavra é a forma latina succidia, ae - substantivo feminino, sentido próprio 1. 'pedaço de carne de porco cortada'; 2 . 'reserva'. ${ }^{6}$

Portanto, como podemos constatar, Carlo Levi tem na linguagem local uma das maiores fontes de informação sobre o espaço vivido e narrado (Lucania, Campania, Sicilia ou Sardenha), acrescentando aos dados colhidos, em passeios, diálogos e visitas, suas con- 
siderações artísticas e afetivas. Em um jogo de analogias e paradoxos, o escritor objetiva documentar, entre outros aspectos, fatos linguísticos de profunda representatividade, que incluem estrangeirismos (pince-nez, réclames, Essais), assim como, na maioria, latinismos e helenismos (jus necationis, temporibus illis, deus ex machina, katoikía (em dialeto 'catoico'), lepis, lépos (em dialeto 'lèppa'), compondo o quadro temático presente/arcaico.

Por meio de sua escritura, que podemos qualificar como constantes diários de viagem, que incluem outros espaços (Rússia, Alemanha, Índia) além da Itália - embora seja esta o espaço mais narrado pelo autor - Carlo Levi "pinta" para seus leitores, terras e gentes profundamente respeitadas por seu espírito humano e solidário, "ressaltando, pela observação dos aspectos da linguagem, pontos de contato e variações espaço-temporais de uma mesma eterna e imutável realidade (A desigualdade social entre o norte e o sul da Itália):

"Das duas Itálias que vivem juntas sobre a mesma terra, esta dos camponeses é certamente aquela mais antiga, que não se sabe de onde tenha vindo, que talvez tenha existido desde sempre. Humilemque vidimus Italiam." (LEVI a, 1990:123)

PRESENTAZIONE: Carlo Levi raggiunge, nel contatto amoroso con le immagini ed i suoni meridionali, il passato arcaico presente, "dipinto" con spontaneità e autenticità, attraverso la gente, le cose e le voci di quello che lui chiama affettuosamente "mia terra" e miei "contadini". 